\title{
Changes in Pore Structure of Coal Caused by $\mathrm{CS}_{2}$ Treatment and Its Methane Adsorption Response
}

\author{
Run Chen $\mathbb{D}^{1,2}{ }^{1,2}$ Yong Qin, ${ }^{2}$ Pengfei Zhang, ${ }^{2}$ and Youyang Wang ${ }^{2}$ \\ ${ }^{1}$ Low Carbon Energy Institute, China University of Mining and Technology (Key Laboratory of Coal-based CO2 Capture \& \\ Geological Storage Jiangsu Province), Xuzhou 221008, China \\ ${ }^{2}$ School of Resource and Geoscience, China University of Mining and Technology (Key Laboratory of Coalbed Methane Resource \& \\ Reservoir Formation History Ministry of Education), Xuzhou 221008, China
}

Correspondence should be addressed to Run Chen; chenrun@cumt.edu.cn

Received 23 January 2018; Revised 6 June 2018; Accepted 15 July 2018; Published 6 August 2018

Academic Editor: Maurizio Barbieri

Copyright (c) 2018 Run Chen et al. This is an open access article distributed under the Creative Commons Attribution License, which permits unrestricted use, distribution, and reproduction in any medium, provided the original work is properly cited.

The pore structure and gas adsorption are two key issues that affect the coal bed methane recovery process significantly. To change pore structure and gas adsorption, 5 coals with different ranks were treated by $\mathrm{CS}_{2}$ for $3 \mathrm{~h}$ using a Soxhlet extractor under ultrasonic oscillation conditions; the evolutions of pore structure and methane adsorption were examined using a highpressure mercury intrusion porosimeter (MIP) with an AutoPore IV 9310 series mercury instrument. The results show that the cumulative pore volume and specific surface area (SSA) were increased after $\mathrm{CS}_{2}$ treatment, and the incremental micropore volume and SSA were increased and decreased before and after $R_{\mathrm{o} \text { max }}=1.3 \%$, respectively; the incremental big pore (greater than $10 \mathrm{~nm}$ in diameter) volumes were increased and SSA was decreased for all coals, and pore connectivity was improved. Methane adsorption capacity on coal before and after $R_{\mathrm{o} \text {, max }}=1.3 \%$ also was increased and decreased, respectively. There is a positive correlation between the changes in the micropore SSA and the Langmuir volume. It confirms that the changes in pore structure and methane adsorption capacity due to $\mathrm{CS}_{2}$ treatment are controlled by the rank, and the change in methane adsorption is impacted by the change of micropore SSA and suggests that the changes in pore structure are better for gas migration; the alteration in methane adsorption capacity is worse and better for methane recovery before and after $R_{\mathrm{o}, \max }=1.3 \%$. A conceptual mechanism of pore structure is proposed to explain methane adsorption capacity on $\mathrm{CS}_{2}$ treated coal around the $R_{\mathrm{o}, \max }=1.3 \%$.

\section{Introduction}

Coal bed methane (CBM) is a serious risk (gas outburst) to safe production in coalmines and also is one of the most important energies in recent decades, but it is not easy to recover due to the low porosity and permeability of the coal seam reservoir. Previous studies have confirmed that coal has a dual pore system including primary porosity consisting of micropore, transitional pore, and mesopore in the coal matrix and second porosity composed of nonuniformly distributed macropore [1-4]. CBM is held to the internal specific surface area (SSA) of coal with absorbed state mainly, and some free gas exists in the natural fractures of coal and some gas dissolves in waters in coal [3-8]. Thus, the quantification of the pore structure is essential to estimating coal bed methane storage capacity and predicting gas production in reservoir conditions.

Various pore characterization techniques have been applied to quantify the pore structures from total porosity, pore volume, pore size distribution (PSD), SSA, and so on $[2,9-15]$. These include low-pressure gas $\left(\mathrm{N}_{2} / \mathrm{CO}_{2}\right)$ adsorption/desorption techniques [9-12], high-pressure mercury intrusion porosimetery (MIP) [12-14], ultra/small-angle neutron scattering (SANS) $[15,16]$, focused ion beam scanning electron microscopy [17], field emission scanning electron microscopy/transmission electron microscopy [18], nuclear magnetic resonance $[19,20]$, and X-ray computed tomography $[17,19,20]$. There are several types of pore classification systems employed for various pore scales in CBM research, including Hodot classification, the classification 
of International Union of Pure and Applied Chemistry (IUPAC), and Gan classification [21-23]. Hodot classification is accepted widely to describe the various scale pores of MIP.

Coal rank is the degree of the transformation of peat through lignite as well as subbituminous, bituminous, semianthracite to anthracite, and meta-anthracite coal, and the rank classes in terms of vitrinite reflectance $\left(R_{\mathrm{o}, \max }\right)$. Many studies have shown that the pore size distribution is affected by the coal rank and there is a U-shaped relationship between the pore size distribution and coal rank [24]. A number of studies concluded that micropores and transitional pores are the primary space for CBM storage, whereas meso- and macropores are responsible for CBM migration [1, 25-31].

Methane adsorption in coal is controlled by internal factors, including coal rank, macerals (vitrinite, exinite, and inertinite), and pore size distribution $[1,26,29,30,32]$, and influenced by external factors, such as temperature, pressure, and humidity $[26,33,34]$. The methane adsorption capacity in coal increases with coal rank and vitrinite content in macerals at high coal ranks, which is because vitrinite is more microporous with a higher SSA than inertinite is $[35,36]$. The SSA of micropore has a positive relationship with $\mathrm{CH}_{4}$ adsorption capacity [37, 38].

Those researches have confirmed the coal seam with low porosity and permeability, and the pore structures (PSDs, SSA, and pore volumes) are controlled by the coal rank and have an important impact on methane adsorption capacity; around $R_{\mathrm{o} \text {, } a x}=1.3 \%$, the evolution tends to change obviously. Only limited studies have quantified the alteration of the pore structure and gas adsorption. In our study, we will try to quantify the effect of the $\mathrm{CS}_{2}$ treatment effect on pore structure and methane adsorption changes with coal rank. Such changes have potential impacts on coal bed methane recovery.

\section{Materials and Methods}

2.1. Coal Samples. The coal samples were collected from undeformed Permian coal seams in Haitian coalmines located in eastern Yunnan Province and Tucheng, Yuni, Linyuan, and Jinjia located in Guizhou Province (Figure 1). All of the samples were wrapped in black polyethylene bags after collection before being transported to the laboratory for analysis. To eliminate the effects of the sedimentology and the parent material of coals, vitrinites were first separated and collected by hand and then pulverized for passage through a 35-mesh sieve. Finally, they were enriched using the heavy liquid floatation method until the vitrinite content was above $85 \%$ (Table 1). The samples were divided into 2 parts. One part was dried for mercury intrusion measurements and methane isothermal adsorption. The second part was treated by $\mathrm{CS}_{2}$ and then was dried for mercury intrusion measurements and methane isothermal adsorption.

2.2. $\mathrm{CS}_{2}$ Treatment. $\mathrm{CS}_{2}$ treatment was conducted using a Soxhlet extractor under ultrasonic oscillation conditions at room temperature using the following procedure with $\mathrm{CS}_{2}$.
First, for each experiment, approximately $20 \mathrm{~g}$ of dry coal was placed into the flat container of the Soxhlet extractor. Then, approximately $600 \mathrm{~mL}$ of $\mathrm{CS}_{2}$ was added, and the extractor was sealed to begin treatment under ultrasonic oscillation. Each $\mathrm{CS}_{2}$ treatment was performed for approximately three hours. After the treatment, the liquid eluents were separated from coal, and the coal was dried at $80^{\circ} \mathrm{C}$. The $\mathrm{CS}_{2}$ treatment was repeated until the mass of each treated coal was greater than $80 \mathrm{~g}$.

2.3. Pore Structure Test. Measurements of the pore structures were conducted using a mercury intrusion porosimeter with an AutoPore IV 9310 series mercury instrument. For the mercury intrusion porosimetry measurements, a contact angle of $140^{\circ}$ and a surface tension of $485 \mathrm{dyn} / \mathrm{cm}$ were assumed. All samples were dried at $80^{\circ} \mathrm{C}$ for at least three hours before the tests.

2.4. Methane Isothermal Adsorption Experiment. Methane isothermal adsorptions on samples were performed using a Laboratory Isotherm Adsorption System on an IS-100 adsorption system. Prior to measurement, the samples were crushed in accordance with the Chinese Standard GB/T 212-2001 and were dried at $80^{\circ} \mathrm{C}$ until the weight loss was less than $1 \%$. The measurements were carried out at $30^{\circ} \mathrm{C}$, and each isothermal adsorption curve includes six different pressures. Approximately $80 \mathrm{~g}$ of each sample was tested, and the adsorbate was $99.99 \%$ methane.

\section{Results and Discussion}

3.1. Pore Structure and Its Evolution. The pore distributions of samples are shown in Figure 2; the incremental macroand mesopores have a very high percentage. It contradicts with the previous understandings [3, 37, 38]. It was regarded that there were so many gaps between sample particles in this study. Due to many gaps between sample particles, the pores that were over $10,000 \mathrm{~nm}$ in diameter were eliminated to reduce the interference on pore structure. Attributed to the lower limitation of $6 \mathrm{~nm}$ for AutoPore IV 9310, a modified Hodot classification was used as follows: micropores $(6 \sim 10 \mathrm{~nm})$, transitional pores $(10 \sim 100 \mathrm{~nm})$, mesopores $(100 \sim 1000 \mathrm{~nm})$, and macropores (1000 10,000 nm).

Previous studies have shown that the incremental macro- and micropores contribute the most to the cumulative pore volume and SSA, respectively [37, 38]. In our study, the cumulative pore volumes range from 0.0207 to $0.2332 \mathrm{~cm}^{3} / \mathrm{g}$ (Table 2), and the cumulative pore SSAs range from 4.7525 to $16.3162 \mathrm{~m}^{2} / \mathrm{g}$ (Table 3 ). The volumes from the incremental macropores and transitional pores account for over $65 \%$ of the cumulative volume, confirming that the big pores are the main contributors for the cumulative pore volume. The SSAs from the incremental transitional and micropores account for over $90 \%$ of the cumulative SSA, confirming that small pores are the main contributors to the cumulative pore SSA. 


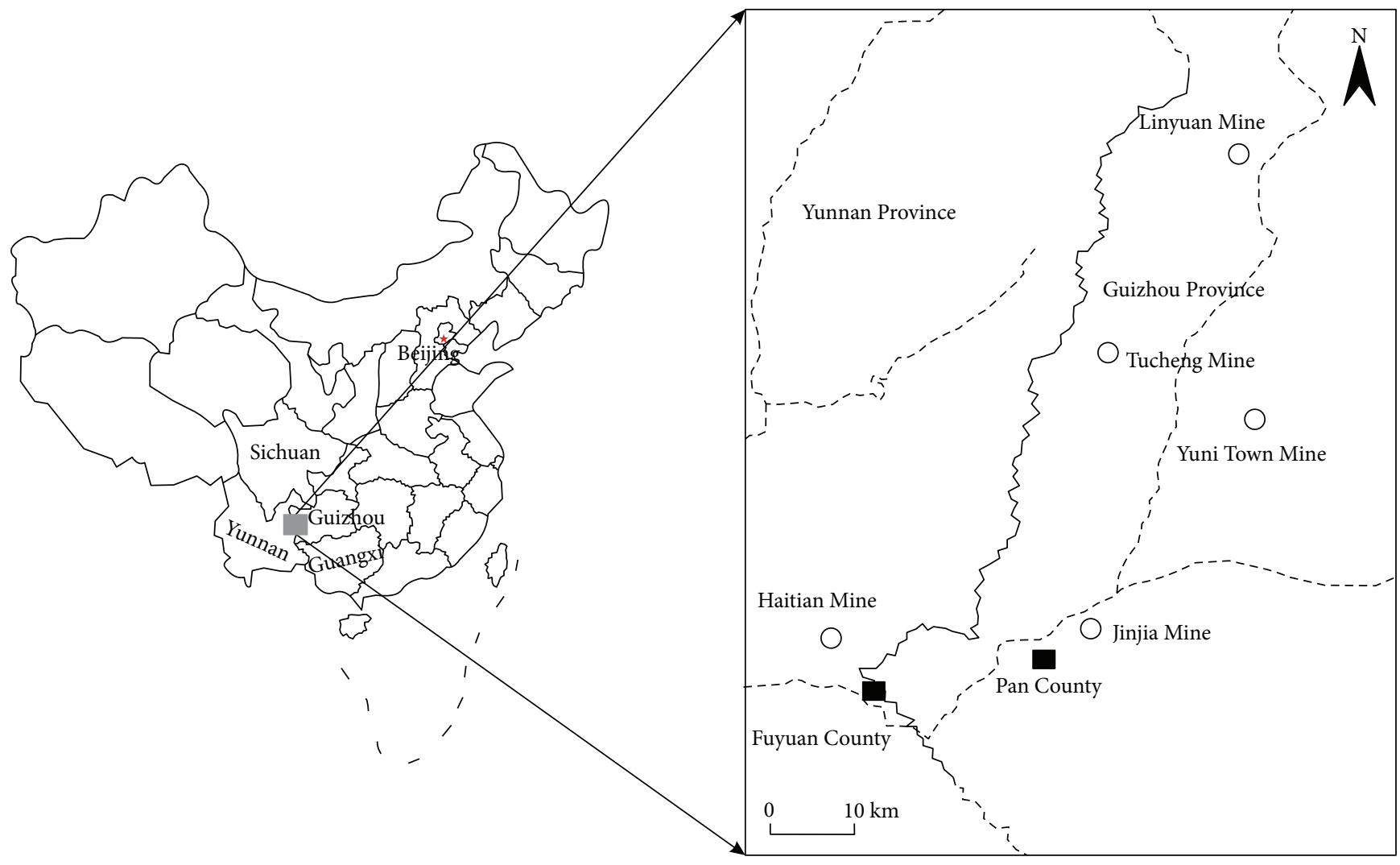

- County

O Sampling location

- Province boundary

- - Railway

-- Highway

FIgURE 1: Locations of coalmines for coal samples collected.

TABLE 1: Vitrinite reflectance, macerals, and proximate analysis.

\begin{tabular}{lccccc}
\hline Samples & Haitian & Tucheng & Yuni & Linyuan & Jinjia \\
\hline$R_{\text {o,max }}(\%)$ & 0.73 & 1.04 & 1.28 & 1.53 & 2.06 \\
Vitrinite (\%) & 95.54 & 87.42 & 85.77 & 89.67 & 93.95 \\
Inertinite (\%) & 0.97 & 3.56 & 0.38 & 0.19 & - \\
Exinite (\%) & 2.91 & 8.54 & 11.39 & 9.37 & 5.68 \\
Mineral (\%) & 0.58 & 0.48 & 2.47 & 0.76 & 0.38 \\
$M_{\text {ad }}(\%)$ & 3.28 & 0.98 & 1.12 & 0.96 & 1.01 \\
$A_{\mathrm{d}}(\%)$ & 3.65 & 7.09 & 6.07 & 4.17 & 8.97 \\
$V_{\text {ad }}(\%)$ & 33.34 & 34.07 & 23.96 & 17.27 & 13.45 \\
\hline
\end{tabular}

To further study the changes in pore volume and SSA caused by $\mathrm{CS}_{2}$ treatment, $\Delta V$ and $\Delta S$ were defined by the following equations, respectively:

$$
\begin{gathered}
\Delta V=V_{\mathrm{t}}-V_{\mathrm{u}}, \\
\Delta S=S_{\mathrm{t}}-S_{\mathrm{u}},
\end{gathered}
$$

where $\Delta V$ is the incremental pore volume change due to $\mathrm{CS}_{2}$ treatment, in $\mathrm{cm}^{3} / \mathrm{g} ; V_{\mathrm{t}}$ and $V_{\mathrm{u}}$ are the incremental pore volumes of the treated coal and the untreated coal, respectively, in $\mathrm{cm}^{3} / \mathrm{g} ; \Delta S$ is the change in the incremental SSA due to the treatment, in $\mathrm{m}^{2} / \mathrm{g} ; S_{\mathrm{t}}$ and $S_{\mathrm{u}}$ are the incremental SSAs of the treated coal and the untreated coal, respectively, in $\mathrm{m}^{2} / \mathrm{g}$.

After $\mathrm{CS}_{2}$ treatment, the incremental pore volumes and SSAs changed substantially. As shown in Figures 3 and 4, $\Delta V_{\mathrm{mi}}$ and $\Delta S_{\mathrm{mi}}$ are positive and negative before and after $R_{\mathrm{o}, \max }=1.3 \%$, respectively; some of $\Delta V_{\mathrm{tr}}$ and $\Delta S_{\mathrm{tr}}$ are positive and the others are negative, demonstrating no obvious regularity. $\Delta V_{\mathrm{ma}}, \Delta V_{\mathrm{me}}, \Delta S_{\mathrm{ma}}$, and $\Delta S_{\mathrm{me}}$ all are positive. Those data indicate that after $\mathrm{CS}_{2}$ treatment, all incremental pore sizes are enlarged, the incremental micropore numbers before $R_{\mathrm{o}, \max }=1.3 \%$ are increased, and the numbers of the incremental micropore and other pores are decreased in all samples.

Previous studies have shown that aliphatic groups containing oxygen link the multilayered stacks and have not yet been dissipated as volatiles at the early stage of 


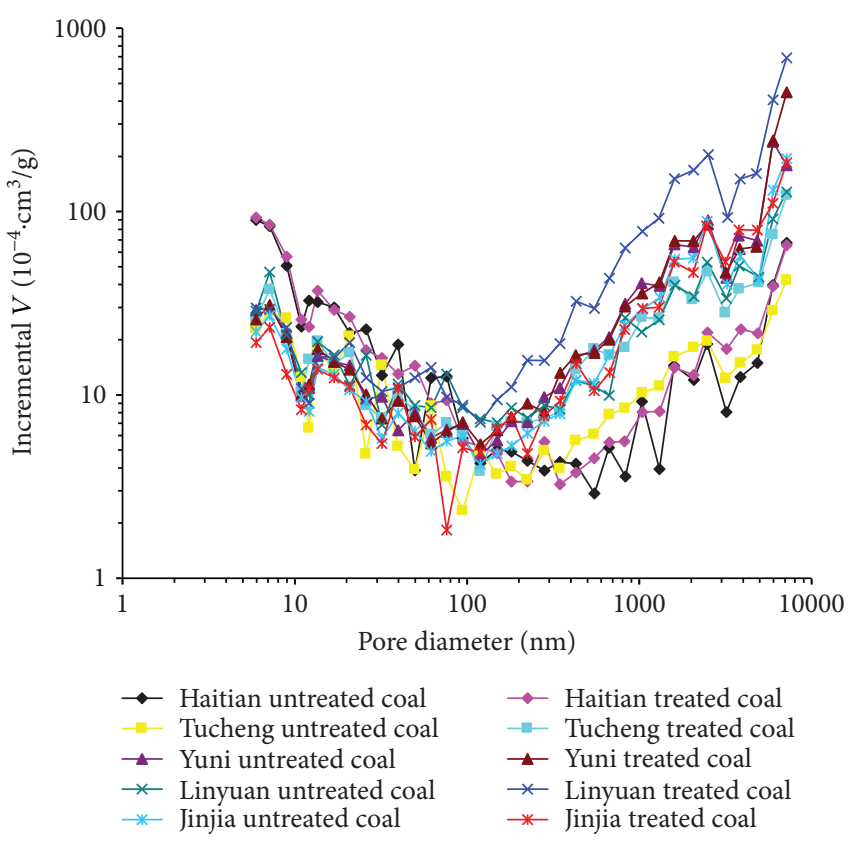

FIgURE 2: Pore size distributions of samples.

TABLe 2: Pore volumes of the untreated and $\mathrm{CS}_{2}$-treated coals.

\begin{tabular}{|c|c|c|c|c|c|c|c|c|c|c|}
\hline \multirow{2}{*}{ Sample } & & \multicolumn{5}{|c|}{ Pore volume $\left(10^{-2} \mathrm{~cm}^{3} / \mathrm{g}\right)$} & \multicolumn{4}{|c|}{ Percentage of pore volume (\%) } \\
\hline & & $V_{\mathrm{ma}}$ & $V_{\text {me }}$ & $V_{\mathrm{tr}}$ & $V_{\mathrm{mi}}$ & $V_{\mathrm{cu}}$ & $V_{\mathrm{ma}}$ & $V_{\text {me }}$ & $V_{\mathrm{tr}}$ & $V_{\mathrm{mi}}$ \\
\hline \multirow{2}{*}{ Haitian coal } & Untreated & 1.9993 & 0.4217 & 2.2700 & 2.2268 & 6.9178 & 28.9005 & 6.0959 & 32.8139 & 32.1897 \\
\hline & $\mathrm{CS}_{2}$-treated & 2.2954 & 0.4452 & 2.2441 & 2.3203 & 7.3050 & 31.4223 & 6.0945 & 30.7201 & 31.7632 \\
\hline \multirow{2}{*}{ Tucheng coal } & Untreated & 1.8898 & 0.5251 & 1.1272 & 0.7675 & 4.3096 & 43.8509 & 12.1844 & 26.1556 & 17.8091 \\
\hline & $\mathrm{CS}_{2}$-treated & 4.7273 & 1.0533 & 1.2954 & 0.8447 & 7.9207 & 59.6829 & 13.2981 & 16.3546 & 10.6645 \\
\hline \multirow{2}{*}{ Yuni coal } & Untreated & 8.9632 & 1.2964 & 1.1858 & 0.8003 & 12.2457 & 73.1947 & 10.5866 & 9.6834 & 6.5354 \\
\hline & $\mathrm{CS}_{2}$-treated & 11.5381 & 1.3212 & 1.2022 & 0.7659 & 14.8274 & 77.8161 & 8.9105 & 8.1080 & 5.1654 \\
\hline \multirow{2}{*}{ Linyuan coal } & Untreated & 5.1626 & 1.0588 & 1.4258 & 0.9565 & 8.6037 & 60.0044 & 12.3063 & 16.5719 & 11.1173 \\
\hline & $\mathrm{CS}_{2}$-treated & 21.7167 & 2.4350 & 1.4867 & 0.8166 & 26.4550 & 82.0892 & 9.2043 & 5.6197 & 3.0868 \\
\hline \multirow{2}{*}{ Jinjia coal } & Untreated & 7.2069 & 0.9851 & 1.0027 & 0.6632 & 9.8579 & 73.1079 & 9.9930 & 10.1715 & 6.7276 \\
\hline & $\mathrm{CS}_{2}$-treated & 7.4285 & 1.0097 & 0.9863 & 0.5505 & 9.9750 & 74.4712 & 10.1223 & 9.8877 & 5.5188 \\
\hline
\end{tabular}

ma: macropore; me: mesopore; tr: transitional pore; mi: micropore; cu: cumulative pore.

TABLE 3: Pore surface areas of the untreated and $\mathrm{CS}_{2}$-treated coals.

\begin{tabular}{|c|c|c|c|c|c|c|c|c|c|c|}
\hline \multirow{2}{*}{ Sample } & & \multicolumn{5}{|c|}{ Pore surface area $\left(\mathrm{m}^{2} / \mathrm{g}\right)$} & \multicolumn{4}{|c|}{ Percentage of pore surface area (\%) } \\
\hline & & $S_{\mathrm{ma}}$ & $S_{\mathrm{me}}$ & $S_{\text {tr }}$ & $S_{\mathrm{mi}}$ & $S_{\mathrm{cu}}$ & $S_{\mathrm{ma}}$ & $S_{\mathrm{me}}$ & $S_{\mathrm{tr}}$ & $S_{\mathrm{mi}}$ \\
\hline \multirow{2}{*}{ Haitian coal } & Untreated & 0.0207 & 0.0592 & 4.3972 & 11.4185 & 15.8956 & 0.1302 & 0.3725 & 27.6630 & 71.8340 \\
\hline & $\mathrm{CS}_{2}$-treated & 0.0242 & 0.0598 & 4.3316 & 11.9007 & 16.3162 & 0.1482 & 0.3663 & 26.5478 & 72.9375 \\
\hline \multirow{2}{*}{ Tucheng coal } & Untreated & 0.0234 & 0.0627 & 2.0713 & 3.7832 & 5.9406 & 0.3944 & 1.0548 & 34.8671 & 63.6843 \\
\hline & $\mathrm{CS}_{2}$-treated & 0.0569 & 0.1080 & 2.3548 & 4.2405 & 6.7602 & 0.8419 & 1.5977 & 34.8331 & 62.7270 \\
\hline \multirow{2}{*}{ Yuni coal } & Untreated & 0.1013 & 0.1236 & 2.0826 & 4.0518 & 6.3593 & 1.5930 & 1.9430 & 32.7487 & 63.7150 \\
\hline & $\mathrm{CS}_{2}$-treated & 0.1134 & 0.1303 & 2.1295 & 3.8570 & 6.2302 & 1.8199 & 2.0913 & 34.1803 & 61.9086 \\
\hline \multirow{2}{*}{ Linyuan coal } & Untreated & 0.0590 & 0.1189 & 2.3850 & 4.8200 & 7.3829 & 0.7997 & 1.6104 & 32.3044 & 65.2855 \\
\hline & $\mathrm{CS}_{2}$-treated & 0.2332 & 0.2209 & 2.3362 & 4.1257 & 6.9160 & 3.3718 & 3.1943 & 33.7796 & 59.6543 \\
\hline \multirow{2}{*}{ Jinjia coal } & Untreated & 0.0823 & 0.0961 & 1.7635 & 3.3377 & 5.2796 & 1.5587 & 1.8202 & 33.4022 & 63.2197 \\
\hline & $\mathrm{CS}_{2}$-treated & 0.0837 & 0.1058 & 1.7652 & 2.7978 & 4.7525 & 1.7616 & 2.2254 & 37.1424 & 58.8702 \\
\hline
\end{tabular}

ma: macropore; me: mesopore; tr: transitional pore; mi: micropore; cu: cumulative pore. 


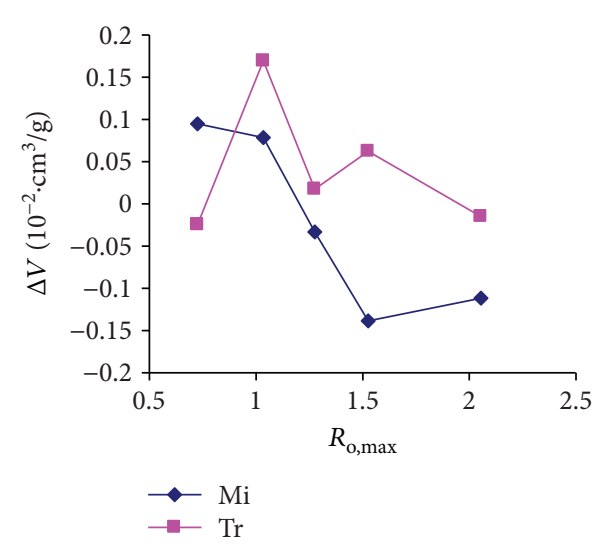

(a)

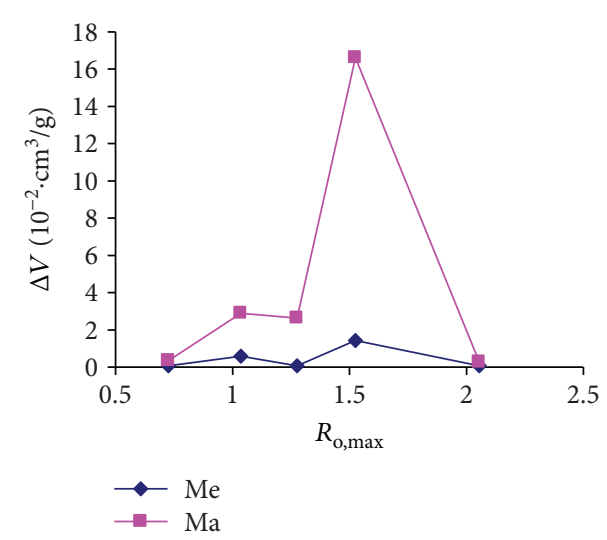

(b)

FIGURE 3: Plots of the changes in pore volume with coal rank: (a) pore volume change in micropore and transitional pore and (b) pore volume change in mesopore and macropore.

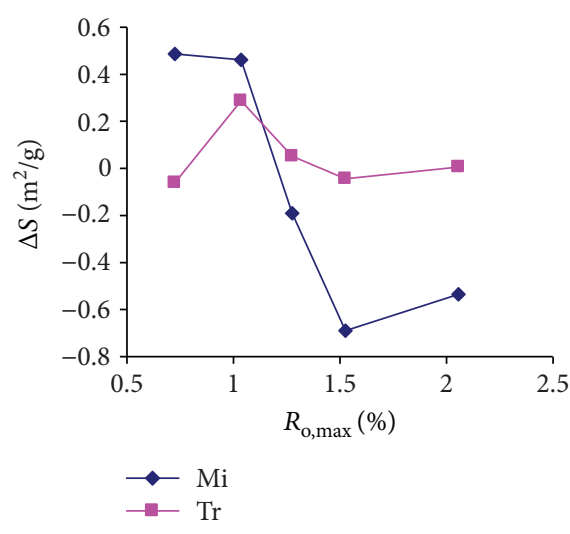

(a)

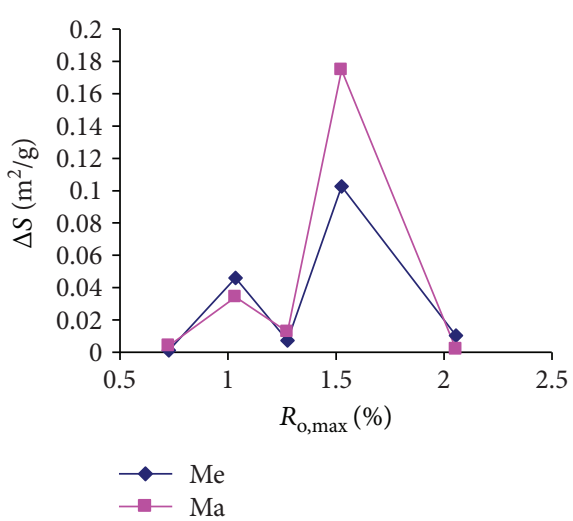

(b)

FIGURE 4: Plots of the changes in SSA with coal rank: (a) SSA change in micropore and transitional pore and (b) SSA change in mesopore and macropore.

coalification [37, 38]. It is compressed with coal rank increasing; the aliphatic groups containing oxygen link the multilayered stacks which began to dissipate and fill the pores and the micropores smaller, and then as maturation advances, oxygen-containing compounds and other volatiles are being lost. It indicates that the changes on pore structure due to $\mathrm{CS}_{2}$ treatment are controlled by the coal rank. The data indicate that the treatment of $\mathrm{CS}_{2}$ has enlarging effect on pore size and increasing effect on pore number. We concluded that the pore size-enlarging effect is the main result of the sample pore volumes, the pore number-increasing effect occurs in the micropores of sample SSAs before $R_{\mathrm{o}, \max }=1.3$ $\%$, and the evaluation of the pore structure due to $\mathrm{CS}_{2}$ treatment is controlled by the coal rank.

Hysteresis between the intrusion and extrusion can use the Ink Bottle theory [39] or connectivity model [13] to interpret. In these theories, pores in samples are rarely of a uniform shape and would be broken at all the throats between pore amounts of mercury trapped inside the sample. A network of pores is used to introduce an additional component considering the connection effects between the pores.
In this study, the hysteresises of the samples were reduced significantly by the treatment of $\mathrm{CS}_{2}$ (Figure 5). It could be explained using the Ink Bottle theory and/or connectivity model. Because of the treatment of $\mathrm{CS}_{2}$, small organic matters filled in open pores may be dissolved and flushed away to cause some incremental pore sizes to be enlarged and the number of incremental micropore to be increased, causing some closed and/or ink bottle pores with small organic matters to open and connect, indicating that $\mathrm{CS}_{2}$ treatment improves the connectivity of the pore; it is better for gas migration during the process of coalbed methane production.

3.2. Methane Isothermal Adsorption Capacity and Its Evolution. Excess methane isothermal adsorption was measured using the volumetric method, and the results are shown in Figure 6. The adsorbed volumes are expressed on a dry ash-free basis. The measured methane adsorption capacities of samples range from 14.99 to $28.87 \mathrm{~cm}^{3} / \mathrm{g}$. Generally, the methane adsorption capacities of untreated coals increase with coal rank increasing, confirming that methane adsorption capacity on untreated coal is affected by the coal rank. 

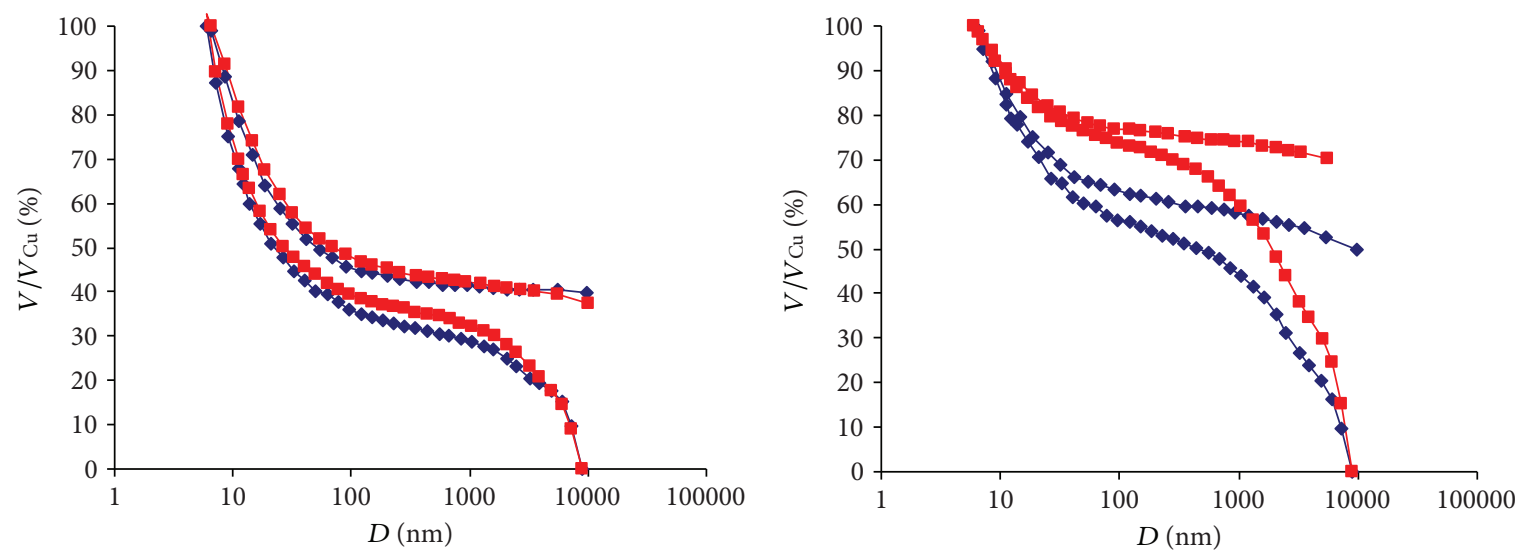

$\multimap$ Haitian untreated coal

$\rightarrow$ Haitian treated coal

$\rightarrow-$ Tucheng untreated coal

$\rightarrow$ Tucheng treated coal

(a)

(b)
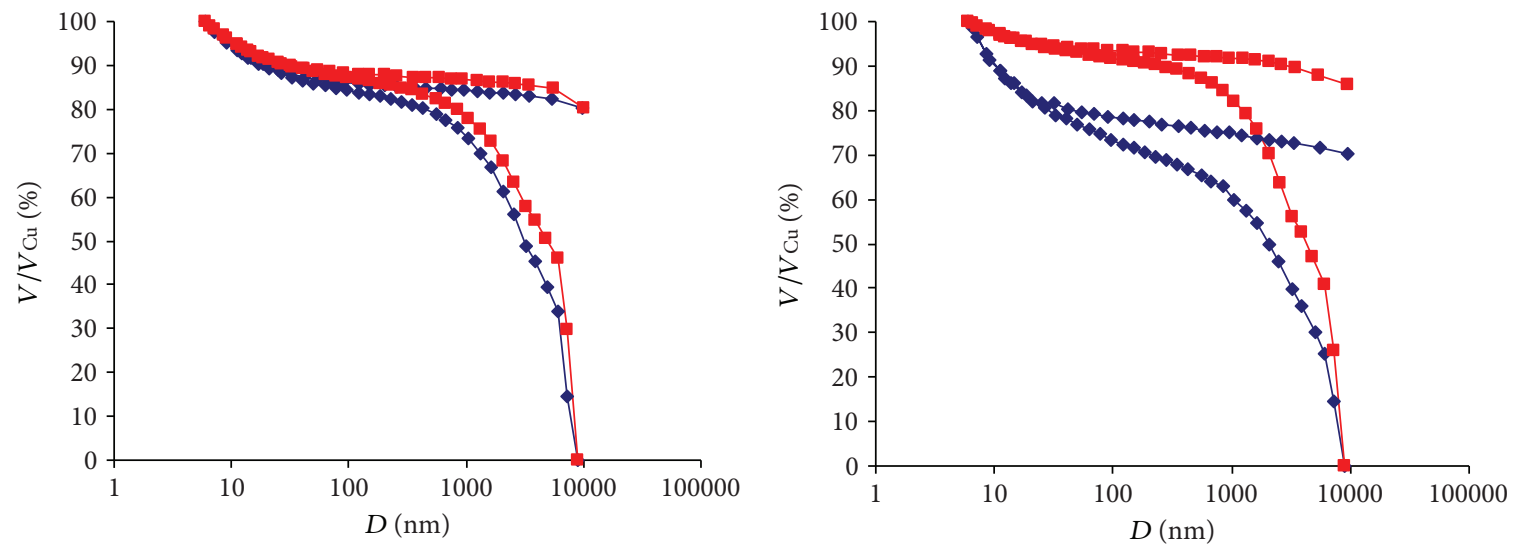

- - Yuni untreated coal

$\rightarrow$ Yuni treated coal

$\rightarrow$ Linyuan untreated coal

$\rightarrow$ Linyuan treated coal

(c)

(d)

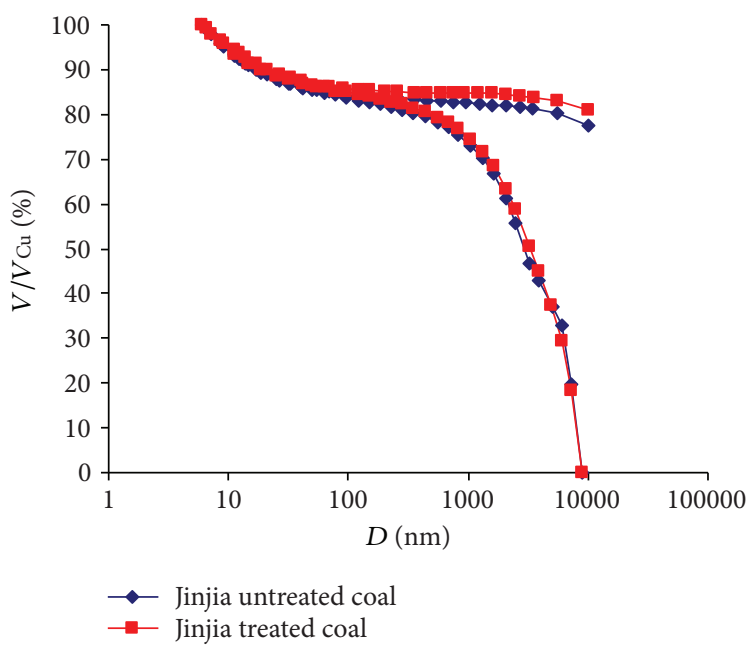

(e)

Figure 5: $V / V_{\mathrm{Cu}}$ of the samples as a function of pore diameter: (a) Haitian samples, (b) Tucheng samples, (c) Yuni samples, (d) Linyuan samples, and (e) Jinjia samples. 


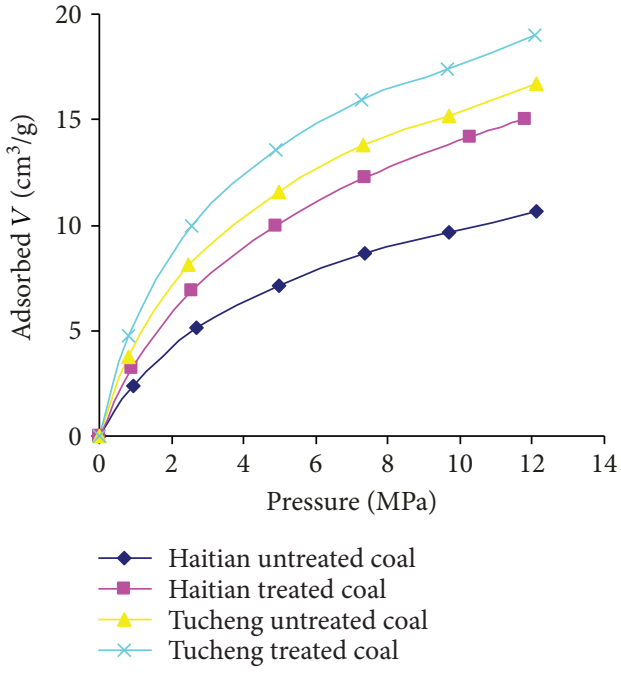

(a)

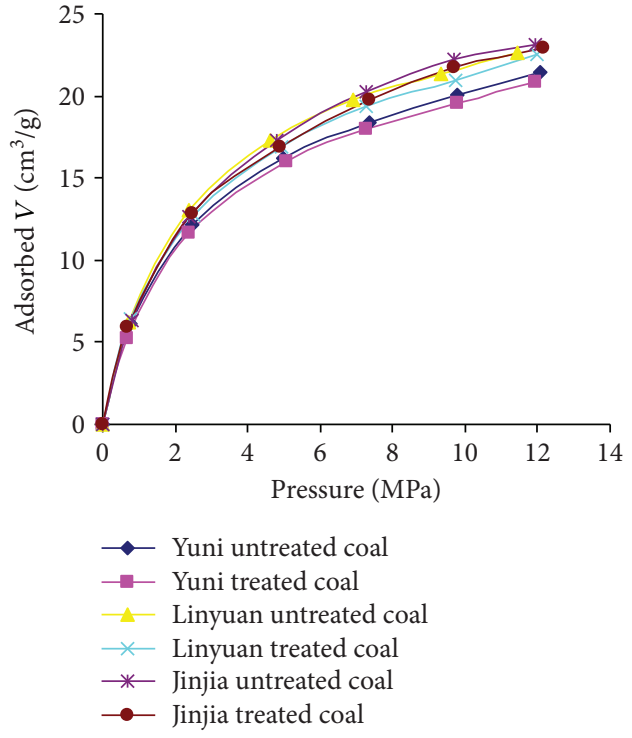

(b)

FIGURE 6: Curves of methane isothermal adsorption on samples: (a) samples of Haitian and Tucheng coals and (b) samples of Yuni, Linyuan, and Jinjia coals.

TABLE 4: Langmuir constants of untreated and $\mathrm{CS}_{2}$-treated coals.

\begin{tabular}{lccc}
\hline Sample & & $V_{\mathrm{L}}\left(\mathrm{cm}^{3} / \mathrm{g}\right)$ & $P_{\mathrm{L}}(\mathrm{MPa})$ \\
\hline \multirow{2}{*}{ Haitian coal } & Untreated & 14.99 & 5.19 \\
& $\mathrm{CS}_{2}$-treated & 21.80 & 5.52 \\
Tucheng coal & Untreated & 22.12 & 4.26 \\
& $\mathrm{CS}_{2}$-treated & 24.05 & 3.53 \\
Yuni coal & Untreated & 25.86 & 2.77 \\
& $\mathrm{CS}_{2}$-treated & 25.23 & 2.75 \\
Linyuan coal & Untreated & 27.46 & 2.60 \\
& $\mathrm{CS}_{2}$-treated & 27.33 & 2.83 \\
Jinjia coal & Untreated $^{*}$ & 28.87 & 3.00 \\
& $\mathrm{CS}_{2}$-treated & 27.89 & 2.82 \\
\hline
\end{tabular}

Based on the curves of the methane adsorption on samples, the Langmuir model can be used to describe the isothermal adsorption curves of the samples:

$$
V=\frac{V_{\mathrm{L}} P}{P_{\mathrm{L}}+P}
$$

where $V$ is the methane adsorption volume at equilibrium conditions, in $\mathrm{cm}^{3} / \mathrm{g} ; P$ is the equilibrium pressure, in $\mathrm{MPa} ; V_{\mathrm{L}}$ is the Langmuir volume at standard state with a pressure of $101 \mathrm{kPa}$ and a temperature of $273.15 \mathrm{~K}$, in $\mathrm{cm}^{3} / \mathrm{g}$; and $P_{\mathrm{L}}$ is the Langmuir pressure, in $\mathrm{MPa}$.

The Langmuir constants of the untreated and $\mathrm{CS}_{2}$-treated coals are shown in Table 4. To further study the changes in methane adsorption capacity that is due to $\mathrm{CS}_{2}$ treatment and the effect on coal bed methane recovery, $\Delta V_{\mathrm{L}}$ and $\Delta P_{\mathrm{L}}$ are defined using the following equations, respectively:

$$
\begin{aligned}
\Delta V_{\mathrm{L}} & =V_{\mathrm{Lt}}-V_{\mathrm{Lu}}, \\
\Delta P_{\mathrm{L}} & =P_{\mathrm{Lt}}-P_{\mathrm{Lu}},
\end{aligned}
$$

where $\Delta V_{\mathrm{L}}$ is the change in $V_{\mathrm{L}}$ due to $\mathrm{CS}_{2}$ treatment, in $\mathrm{cm}^{3} / \mathrm{g}$; $V_{\mathrm{Lt}}$ and $V_{\mathrm{Lu}}$ are the $V_{\mathrm{L}}$ for $\mathrm{CS}_{2}$-treated coal and untreated coal, respectively, in $\mathrm{cm}^{3} / \mathrm{g} ; \Delta P_{\mathrm{L}}$ is the change in $P_{\mathrm{L}}$ due to the treatment, in $\mathrm{MPa}$; and $\Delta P_{\mathrm{Lt}}$ and $\Delta P_{\mathrm{Lu}}$ are the $P_{\mathrm{L}}$ for $\mathrm{CS}_{2}$-treated coal and untreated coal, respectively, $\mathrm{MPa}$.

As shown in Figure 7, after $\mathrm{CS}_{2}$ treatment, the $\Delta V_{\mathrm{L}}$ of Haitian coal and Tucheng coal is positive, while that of other coal samples is negative (Figure $7(\mathrm{a})$ ). The $\Delta P_{\mathrm{L}}$ of Haitian coal and Linyuan coal is positive and that of others is negative (Figure 7(b)). Thus, the treatment of $\mathrm{CS}_{2}$ increased and decreased the methane adsorption capacities in coals before and after $R_{\mathrm{o}, \max }=1.3 \%$, respectively, and there was no consistent trend for $\Delta P_{\mathrm{L}}$. The changes in the methane adsorption capacities due to $\mathrm{CS}_{2}$ treatment are controlled by the coal rank, which indicates that $\mathrm{CS}_{2}$ could be used for ECBM recovery for coals after $R_{\mathrm{o}, \max }=1.3 \%$ from the view of methane adsorption, but not for low-rank coals.

3.3. Effects of Pore Structure Changes on Methane Adsorption Capacity. The effect of pore structure changes due to $\mathrm{CS}_{2}$ treatment on the methane adsorption capacities are shown in Figure 8. $\Delta V_{\mathrm{L}}$ increased when $\Delta S_{\mathrm{mi}}$ increased, and there is no relation to $\Delta S_{\mathrm{tr}}, \Delta S_{\mathrm{me}}, \Delta S_{\mathrm{ma}}$, and $\Delta V$. Previous studies have shown that the methane adsorption capacity in coal is primarily controlled by the magnitude of the pore SSA, and the pore SSA is controlled by the coal rank and influenced by the maceral composition [37, 40]. In this study, the relation of $\Delta V_{\mathrm{L}}$ to $\Delta V$ and $\Delta S$ shows that the methane 


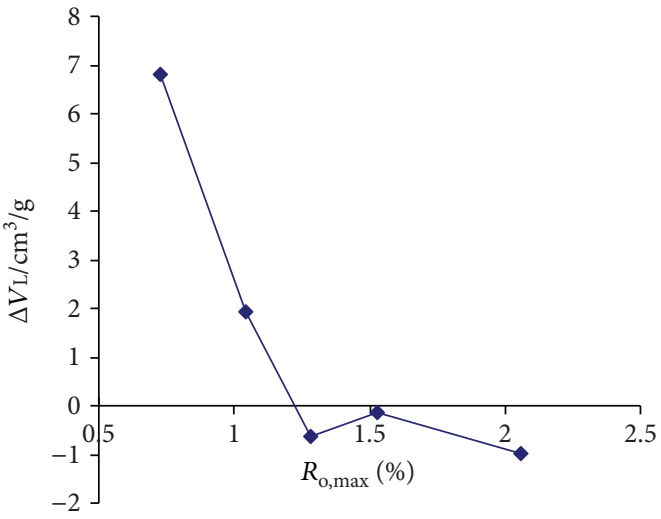

(a)

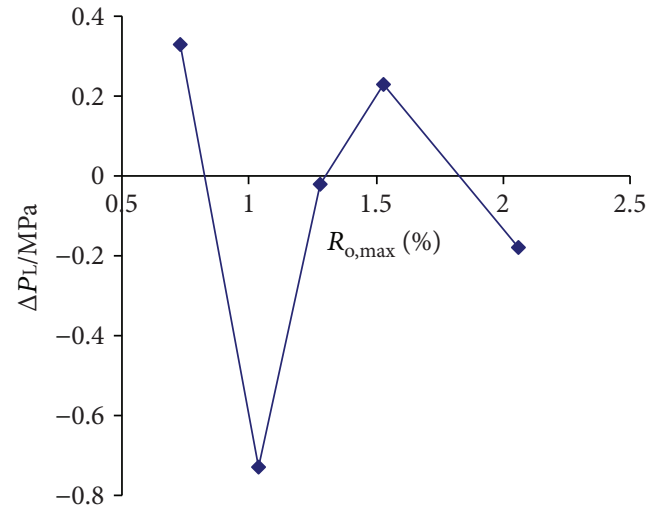

(b)

FIGURE 7: Methane isothermal adsorption constant changes with the coal rank increasing: (a) $\Delta V_{\mathrm{L}}$ changes with the coal rank increasing and (b) $\Delta P_{\mathrm{L}}$ changes with the coal rank increasing.

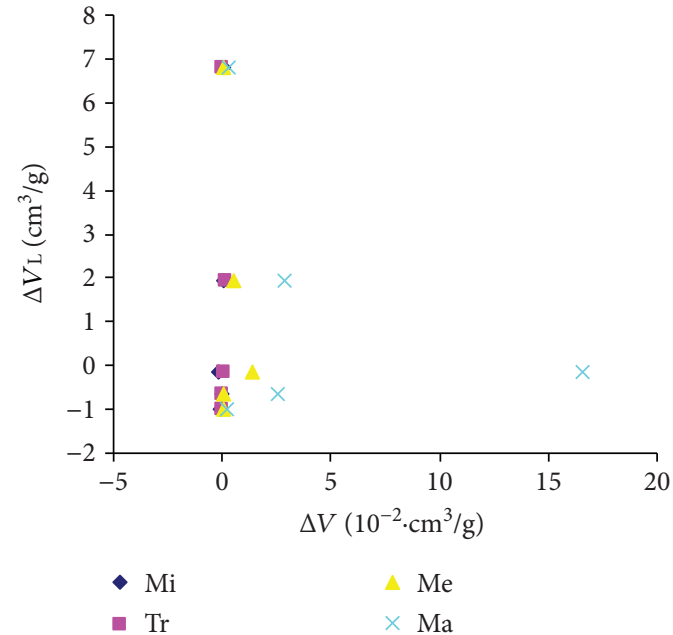

(a)

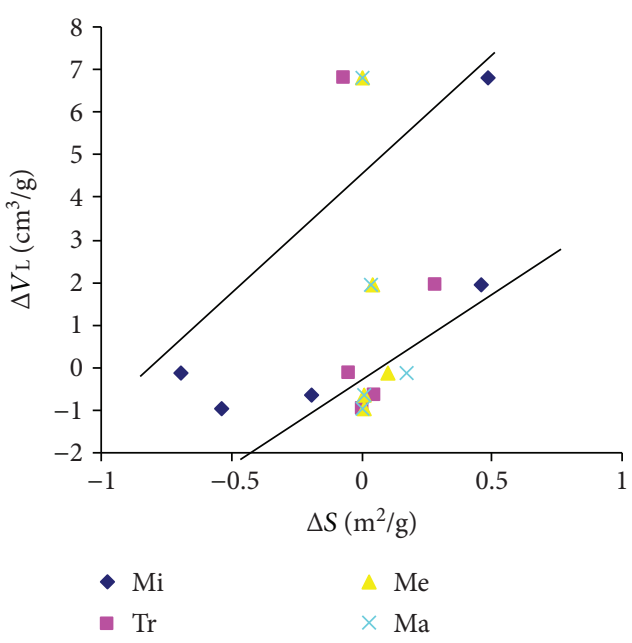

(b)

FIGURE 8: $\Delta V_{\mathrm{L}}$ versus $\Delta V$ and $\Delta S$ : (a) $\Delta V_{\mathrm{L}}$ changes with $\Delta V$ increasing and (b) $\Delta V_{\mathrm{L}}$ changes with $\Delta S$ increasing.

adsorption capacity is closely related to the micropore SSA, demonstrating that the pore number is increased for coal before $R_{\mathrm{o}, \max }=1.3 \%$ and the pore size is enlarged in all diameters for all coals due to $\mathrm{CS}_{2}$ treatment. It also confirms that the changes of pore structures and methane adsorption capacities due to $\mathrm{CS}_{2}$ treatment are controlled by the coal rank.

3.4. A Conceptual Pore Structure Evolution Model with $\mathrm{CS}_{2}$ Treatment. As previously mentioned, the discrepancy in the sense of the change in pore structure may be attributed to changes in the size and connectivity of the micron-scale inaccessible pores. Lee's study has provided evidence that the amount of normal alkanes drops at the early stage of coalification, then fill in pores and cause the size of small pores to be reduced; as maturation advances, more methane is generated and normal alkanes are lost [41]. Therefore, there are some differences in pore structure changes for $\mathrm{CS}_{2}$-treated coal before and after $R_{\mathrm{o}, \max }=1.3 \%$. A conceptual model for pore structure evolution resulting from $\mathrm{CS}_{2}$ treatment is proposed, as shown in Figure 9. Due to $\mathrm{CS}_{2}$ treatment, some closed and or ink bottle pores filled with small organic molecules of coal open and connect before $R_{\mathrm{o}, \max }=1.3 \%$, and the amount of micropores which can be measured by MIP was increased (Figure 9(a)); the pore sizes were enlarged in all coals (Figures 9(a) and 9(b)), and the connectivity of the pores was improved (Figure 9(c)). However, further studies will be needed to confirm this hypothesis for the changes in pore structures of coal caused by $\mathrm{CS}_{2}$ treatment.

Studies have shown that there is a positive relation between micropore SSA and methane adsorption $[1,26,29$, 32]. In this study, after $\mathrm{CS}_{2}$ treatment, the change in methane adsorption capacity on coal before and after $R_{\mathrm{o}, \max }=1.3 \%$ is increased and decreased, which confirms the changes in pore structure due to $\mathrm{CS}_{2}$ treatment.

\section{Conclusions}

Alteration of the pore structure for 5 sets of untreated and $\mathrm{CS}_{2}$-treated coals was characterized by MIP, and methane 

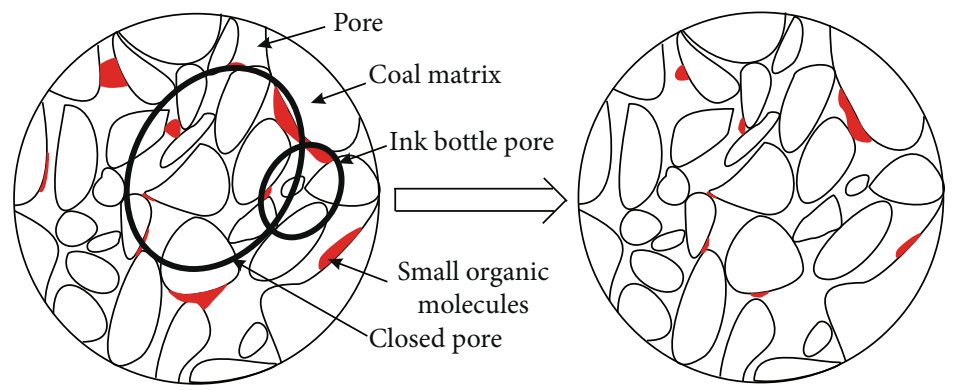

(a)
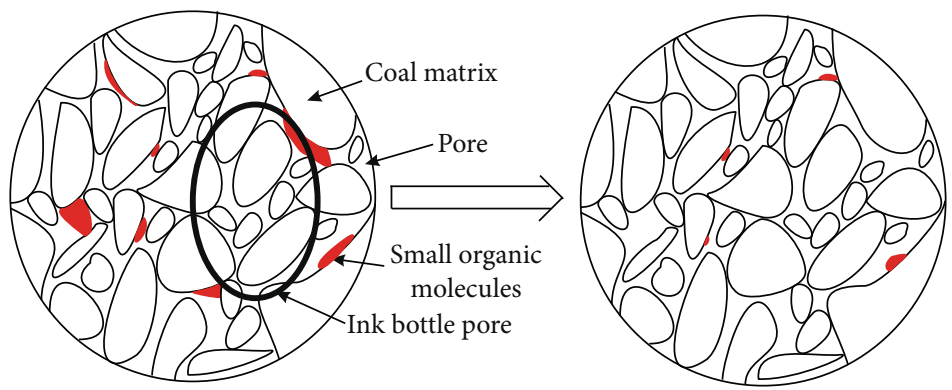

(b)
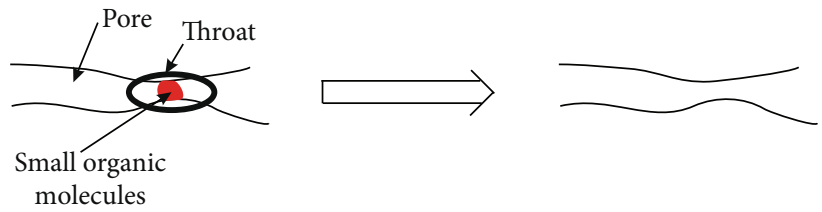

(c)

Figure 9: A conceptual mechanism of pore structure for $\mathrm{CS}_{2}$-treated coal. (a) Pore structure changes for $\mathrm{CS}_{2}$-treated coal before $R_{\mathrm{o} \text {,max }}=1.3 \%$; (b) pore structure changes for $\mathrm{CS}_{2}$-treated coal after $R_{\mathrm{o}, \max }=1.3 \%$; (c) the change of pore connectivity of $\mathrm{CS}_{2}$-treated coal.

adsorption capacity was estimated by the volumetric method. Based on these results, several conclusions are summarized as below:

(1). After $\mathrm{CS}_{2}$ treatment, the cumulative pore volume and SSA were increased, and the incremental micropore volume and SSA were increased and decreased before and after $R_{\mathrm{o}, \max }=1.3 \%$, respectively; the incremental big pore (greater than $10 \mathrm{~nm}$ in diameter) volumes were increased and SSA were decreased for all coals, and pore connectivity was improved. The pore number is increased for coal before $R_{\mathrm{o}, \max }$ $=1.3 \%$, and the pore size is enlarged in all diameters for all coals due to $\mathrm{CS}_{2}$ treatment; the changes are controlled by the coal rank. The change in pore structure is better for gas migration.

(2). Methane adsorption isotherms of $\mathrm{CS}_{2}$ treatment coals followed the Langmuir model. After $\mathrm{CS}_{2}$ treatment, the methane adsorption capacity on coal is increased and decreased before and after $R_{0, \max }=1.3 \%$, which indicates that the change in methane adsorption capacity due to $\mathrm{CS}_{2}$ treatment is controlled by the coal rank, and the solvent of $\mathrm{CS}_{2}$ can be used to enhance coal bed methane recovery for the coal after $R_{\mathrm{o}, \max }=1.3 \%$. The alteration in methane adsorption capacity is worse and better for methane recovery before and after $R_{\mathrm{o} \text { max }}=1.3 \%$.

(3). There is a positive relationship between $\Delta V_{\mathrm{L}}$ and $\Delta$ $S_{\mathrm{mi}}$, while there is no obvious relation with $\Delta V_{\mathrm{L}}$ and other $\Delta S$, confirming that the pore number is increased for coal before $R_{0, \max }=1.3 \%$ and the pore size is enlarged in all diameters for all coals due to $\mathrm{CS}_{2}$ treatment.

(4). A conceptual mechanism of the effect of $\mathrm{CS}_{2}$ treatment coal is proposed which is consistent with the observed evolution of the pore structure and methane adsorption response.

\section{Data Availability}

The data used to support the findings of this study are available from the corresponding author upon request.

\section{Conflicts of Interest}

The authors declare that they have no conflicts of interest. 


\section{Acknowledgments}

The authors would like to thank various organizations for the financial support. This work was jointly supported by the National Natural Science Foundation of China (no. 41572138) and the research fund of Jiangsu Key Laboratory of Coal-based $\mathrm{CO}_{2}$ Capture and Geological Storage (China University of Mining and Technology) (no. 2017A04). The authors thank the editor and reviewers for their detailed comments and suggestions.

\section{References}

[1] C. R. Clarkson and R. M. Bustin, "The effect of pore structure and gas pressure upon the transport properties of coal: a laboratory and modeling study. 2. Adsorption rate modeling," Fuel, vol. 78, no. 11, pp. 1345-1362, 1999.

[2] R. Zhang, S. Liu, J. Bahadur et al., "Changes in pore structure of coal caused by coal-to-gas bioconversion," Scientific Reports, vol. 7, no. 1, p. 3840, 2017.

[3] X. H. Fu, Y. Qin, and C. T. Wei, Coalbed Methane Geology, China University of Mining and Technology Press, Xuzhou, China, 2007.

[4] R. Rogers, K. Ramurthy, G. Rodvelt, and M. Mullen, Coalbed Methane: Principles and Practices, Oktibbeha Publishing CO.,LLC, Starkville MS, USA, Second edition, 2007.

[5] X. Li, X. Fu, A. Liu et al., "Methane adsorption characteristics and adsorbed gas content of low-rank coal in China," Energy \& Fuels, vol. 30, no. 5, pp. 3840-3848, 2016.

[6] Y. Y. Feng, W. Yang, and W. Chu, "Coalbed methane adsorption and desorption characteristics related to coal particle size," Chinese Physics B, vol. 25, no. 6, article 068102, 2016.

[7] R. Chen, X. B. Su, and X. Y. Lin, "Application of Henry Law in solution fractionation of multi-composition coalbed gas," Coal Geology \& Exploration, vol. 35, pp. 31-33, 2007.

[8] L. C. Bonham, "Solubility of methane in water at elevated temperatures and pressures: geologic notes," AAPG Bulletin, vol. 62, pp. 2478-2481, 1978.

[9] Y. Cai, D. Liu, Z. Pan, Y. Yao, J. Li, and Y. Qiu, "Pore structure and its impact on $\mathrm{CH}_{4}$ adsorption capacity and flow capability of bituminous and subbituminous coals from Northeast China," Fuel, vol. 103, pp. 258-268, 2013.

[10] G. Amarasekera, M. J. Scarlett, and D. E. Mainwaring, "Micropore size distributions and specific interactions in coals," Fuel, vol. 74, no. 1, pp. 115-118, 1995.

[11] D. Cazorla-Amorós, J. Alcañiz-Monge, and A. Linares-Solano, "Characterization of Activated Carbon Fibers by CO2Adsorption,” Langmuir, vol. 12, no. 11, pp. 2820-2824, 1996.

[12] W. Yang, Y. Zhu, and S. Liu, "Rui Zhang pore characterization and its impact on methane adsorption capacity for organicrich marine shales," Fuel, vol. 181, pp. 227-237, 2016.

[13] C. D. Tsakiroglou and A. C. Payatakes, "Mercury intrusion and retraction in model porous media," Advances in Colloid and Interface Science, vol. 75, no. 3, pp. 215-253, 1998.

[14] R. Chen, Y. Qin, C. Wei, L. Wang, Y. Wang, and P. Zhang, "Changes in pore structure of coal associated with $\mathrm{Sc}-\mathrm{CO}_{2}$ extraction during $\mathrm{CO}_{2}$-ECBM," Applied Sciences, vol. 7, no. 9, p. 931, 2017.

[15] M. J. Tricker, A. Grint, G. J. Audley, S. M. Church, V. S. Rainey, and C. J. Wright, “Application of small-angle neutron scattering (SANS) to the study of coal porosity," Fuel, vol. 62, no. 9, pp. 1092-1096, 1983.

[16] A. P. Radlinski, M. Mastalerz, A. L. Hinde et al., "Application of SAXS and SANS in evaluation of porosity, pore size distribution and surface area of coal," International Journal of Coal Geology, vol. 59, no. 3-4, pp. 245-271, 2004.

[17] S. Liu, S. Sang, G. Wang et al., "FIB-SEM and X-ray CT characterization of interconnected pores in high-rank coal formed from regional metamorphism," Journal of Petroleum Science and Engineering, vol. 148, pp. 21-31, 2017.

[18] B. G. Kutchko, A. L. Goodman, E. Rosenbaum, S. Natesakhawat, and K. Wagner, "Characterization of coal before and after supercritical $\mathrm{CO}_{2}$ exposure via feature relocation using field-emission scanning electron microscopy," Fuel, vol. 107, pp. 777-786, 2013.

[19] S. Li, D. Tang, H. Xu, and Z. Yang, "Advanced characterization of physical properties of coals with different coal structures by nuclear magnetic resonance and X-ray computed tomography," Computational Geosciences, vol. 48, pp. 220-227, 2012.

[20] Y. Yao, D. Liu, Y. Che, D. Tang, S. Tang, and W. Huang, "Petrophysical characterization of coals by low-field nuclear magnetic resonance (NMR)," Fuel, vol. 89, no. 7, pp. 13711380, 2010.

[21] B. B. Hodot, Outburst of Coal and Gas (Chinese Translation), China Industry Press, Beijing, China, 1966.

[22] M. Thommes, K. Kaneko, A. V. Neimark et al., "Physisorption of gases, with special reference to the evaluation of surface area and pore size distribution (IUPAC technical report)," Pure and Applied Chemistry, vol. 87, no. 9-10, 2015.

[23] H. Gan, S. P. Nandi, and P. L. Walker Jr, "Nature of the porosity in American coals," Fuel, vol. 51, no. 4, pp. 272-277, 1972.

[24] Q. X. Yu, Mine Gas Prevention and Control, China University of Mining and Technology press, Xuzhou, China, 1992.

[25] J. H. Levy, S. J. Day, and J. S. Killingley, "Methane capacities of Bowen basin coals related to coal properties," Fuel, vol. 76, no. 9, pp. 813-819, 1997.

[26] S. Day, R. Sakurovs, and S. Weir, "Supercritical gas sorption on moist coals," International Journal of Coal Geology, vol. 74, no. 3-4, pp. 203-214, 2008.

[27] L. P. Zhang, X. B. Su, and R. S. Zeng, "Discussion on the controlling effects of coal properties on coal adsorption capacity," Acta Geologica Sinica, vol. 80, pp. 910-915, 2006.

[28] Y. J. Cui, X. L. Yang, and Q. L. Zhang, "Characteristics of supercritical methane adsorption on coal," Natural Gas Industry, vol. 23, pp. 131-133, 2003.

[29] C. Laxminarayana and P. J. Crosdale, "Controls on methane sorption capacity of Indian coals," AAPG Bulletin, vol. 86, pp. 201-212, 2002.

[30] C. R. Clarkson and R. Marc Bustin, "Variation in micropore capacity and size distribution with composition in bituminous coal of the Western Canadian sedimentary basin," Fuel, vol. 75, no. 13, pp. 1483-1498, 1996.

[31] R. M. Bustin and C. R. Clarkson, "Geological controls on coalbed methane reservoir capacity and gas content," International Journal of Coal Geology, vol. 38, no. 1-2, pp. 3-26, 1998.

[32] R. Chen, Y. Qin, and C. T. Wei, "Difference in pore structures and adsorptivity between raw and two-step-solvent -extracted vitrains," Natural Gas Geoscience, vol. 25, pp. 1103-1110, 2014. 
[33] Y. Qin, Q. Y. Song, and X. H. Fu, "Discussion on reliability for co-mining the coalbed gas and normal petroleum and natural gas: absorptive effect of deep coal reservoir under condition of balanced water," Natural Gas Geoscience, vol. 16, pp. 492-498, 2005.

[34] B. M. Krooss, F. van Bergen, Y. Gensterblum, N. Siemons, H. J. M. Pagnier, and P. David, "High-pressure methane and carbon dioxide adsorption on dry and moisture-equilibrated Pennsylvanian coals," International Journal of Coal Geology, vol. 51, no. 2, pp. 69-92, 2002.

[35] D. Yee, J. P. Seidle, and W. B. Hanson, "Gas sorption on coal and measurement of gas content," in Hydrocarbons from Coal, B. E. Law and D. D. Rice, Eds., pp. 327-368, AAPG Studies in Geology, 1993.

[36] M. N. Lamberson and R. March Bus, "Coalbed methane characteristics of gates formation coals, Northeastern British Columbia: effect of maceral composition," AAPG Bulletin, vol. 77, pp. 2062-2072, 1993.

[37] L. W. Zhong, "Adsorptive capacity of coals and its affecting factors," Earth Science, vol. 29, pp. 327-334, 2004.

[38] L. R. Radovic, V. C. Menon, C. A. L. Y. Leon et al., "On the porous structure of coals: evidence for an interconnected but constricted micropore system and implications for coalbed methane recovery," Adsorption, vol. 3, no. 3, pp. 221-232, 1997.

[39] C. Salmas and G. Androutsopoulos, "Mercury porosimetry: contact angle hysteresis of materials with controlled pore structure," Journal of Colloid and Interface Science, vol. 239, no. 1, pp. 178-189, 2001.

[40] K. Jian, X. Fu, Y. Ding, H. Wang, and T. Li, "Characteristics of pores and methane adsorption of low-rank coal in China," Journal of Natural Gas Science and Engineering, vol. 27, pp. 207-218, 2015.

[41] M. L. Lee, "Appraisal of the heavy hydrocarbons in coal," Quarterly Review of Methane from Coalseams Technology, vol. 8, no. 4, pp. 45-47, 1991. 

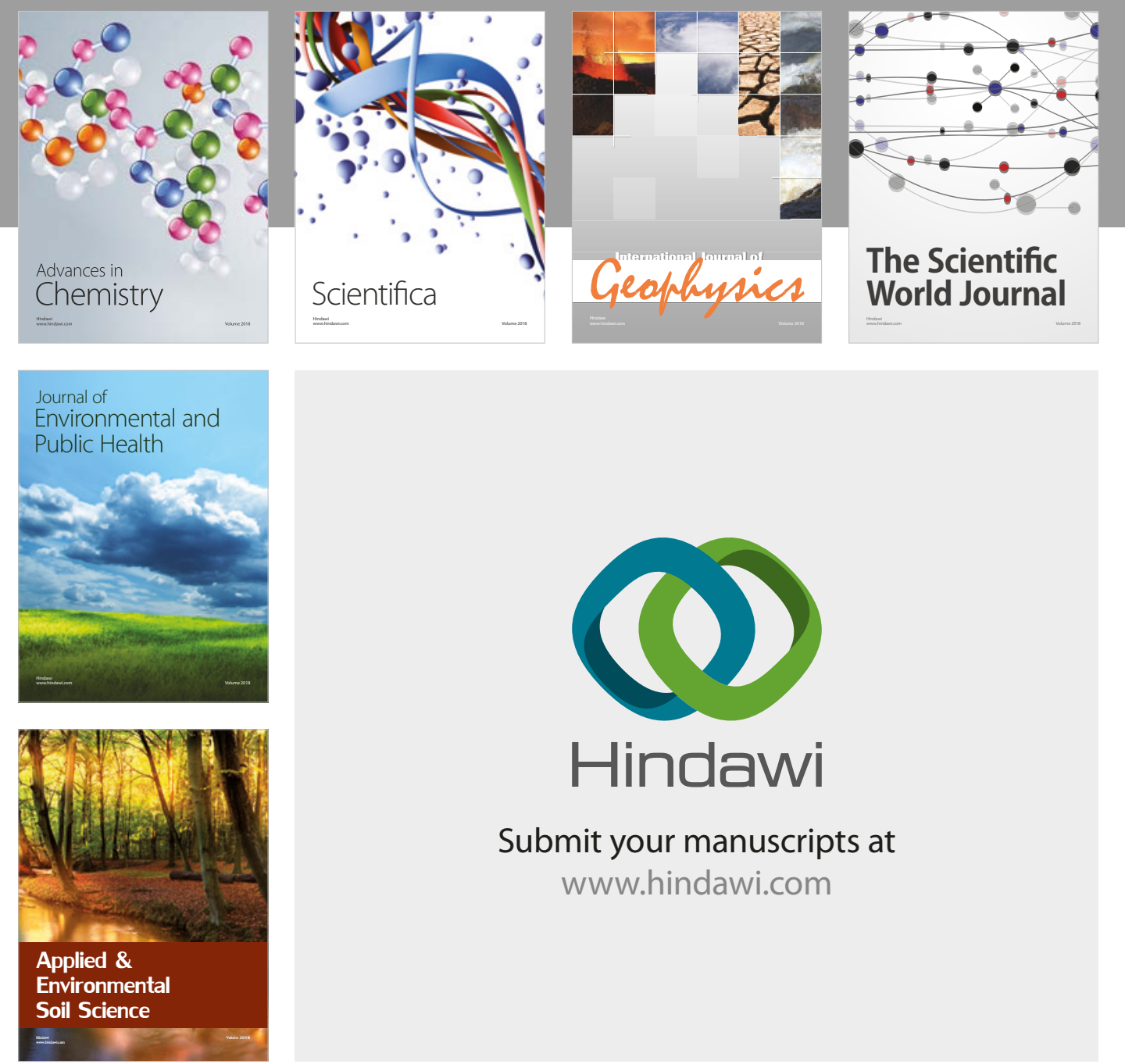

The Scientific

\section{World Journal}
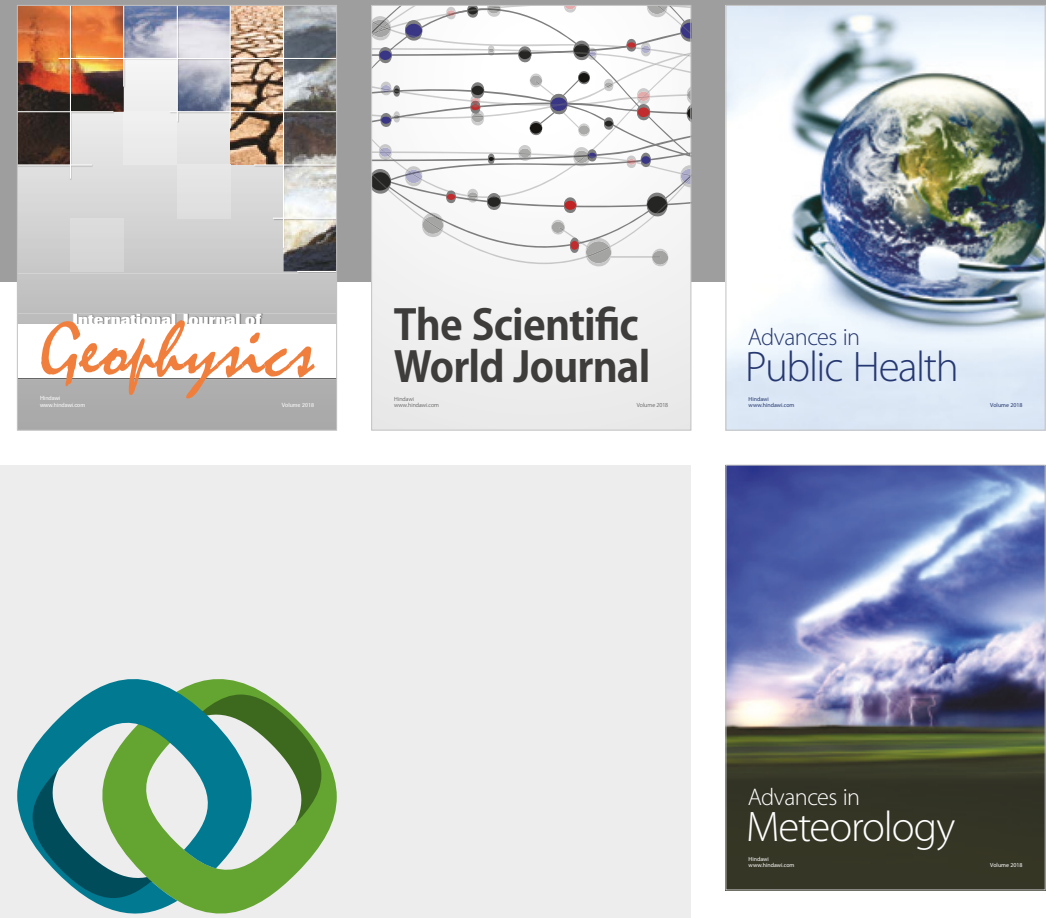

Advan

Public Health

\section{Hindawi}

Submit your manuscripts at

www.hindawi.com
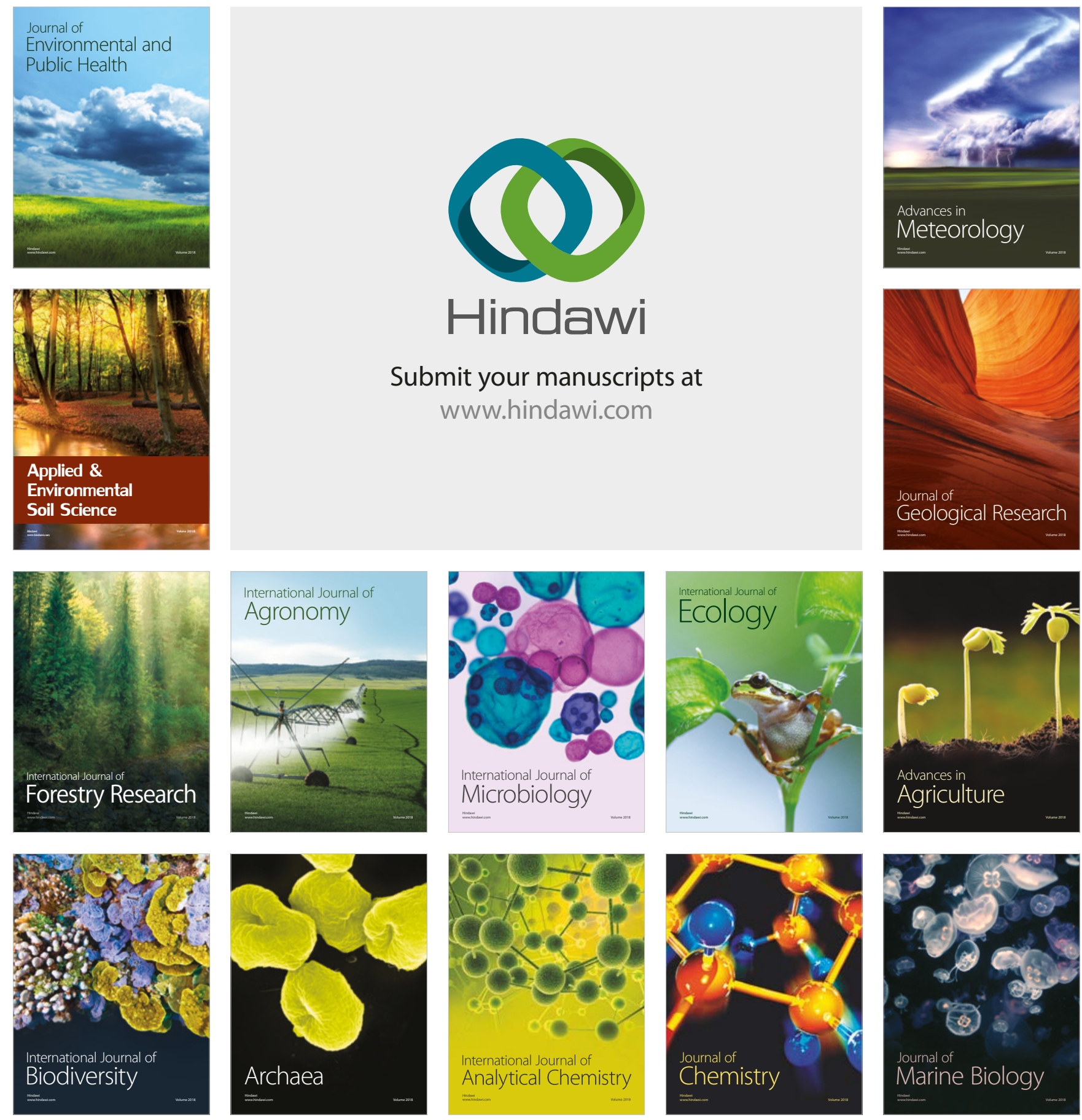